\section{Case Reports in Dermatology}

Case Rep Dermatol 2017;9:13-18

DOI: $10.1159 / 000475878$

Published onlıne: IVlay 22, 2017
(C) 2017 The Author(s)

Published by S. Karger AG, Basel

www.karger.com/cde

This article is licensed under the Creative Commons Attribution-NonCommercial 4.0 International License (CC BY-NC) (http://www.karger.com/Services/OpenAccessLicense). Usage and distribution for commercial purposes requires written permission.

\title{
Sweet's Syndrome Successfully Treated with Granulocyte and Monocyte Adsorption Apheresis
}

\author{
Asami Fujii $^{\mathrm{a}}$ Yoko Mizutani $^{\mathrm{a}}$ Yuki Hattori $^{\mathrm{a}}$ Tomoko Takahashi $^{\mathrm{a}}$ \\ Hidenori Ohnishi $^{b}$ Shozo Yoshida ${ }^{c}$ Mariko Seishima ${ }^{a}$ \\ ${ }^{a}$ Department of Dermatology, Gifu University Graduate School of Medicine, Gifu, Japan; \\ ${ }^{b}$ Department of Pediatrics, Gifu University Graduate School of Medicine, Gifu, Japan; \\ 'Department of Emergency and Disaster Medicine, Gifu University Graduate School of \\ Medicine, Gifu, Japan
}

\section{Keywords}

Granulocyte colony-stimulating factor - Granulocyte and monocyte adsorption apheresis .

Sweet's syndrome . Acute febrile neutrophilic dermatosis

\begin{abstract}
Sweet's syndrome is a neutrophilic dermatosis characterized by an abrupt onset of painful erythematous lesions showing neutrophilic infiltrates in the dermis. Fever and an elevated neutrophil level are generally observed. Sweet's syndrome may be idiopathic, malignancyassociated, or drug-induced (mainly involving granulocyte colony-stimulating factor (G-CSF) administration). Although systemic corticosteroids are usually effective, the symptoms of Sweet's syndrome recur in some refractory cases. Herein, we report a case of a 55-year-old Japanese woman with recurrent symptoms of fever $\left(>39^{\circ} \mathrm{C}\right)$ and painful erythematous lesions on her four extremities, trunk, and neck. Laboratory findings revealed leukocytosis and high levels of C-reactive protein (CRP) and G-CSF. She was diagnosed with a recurrence of Sweet's syndrome, and was exclusively treated with granulocyte and monocyte adsorption apheresis (GMA) therapy once a week for 3 consecutive weeks. After the first session of GMA therapy, all symptoms including the erythematous lesions and fever were completely resolved, and serum G-CSF level was reduced. Leukocyte count, neutrophil count, serum amyloid A protein, and CRP levels were restored within normal ranges by 2 weeks. Thus, GMA therapy can successfully treat a patient with recurrent Sweet's syndrome, potentially related to the restoration of elevated serum G-CSF levels.

(C) 2017 The Author(s)

Published by S. Karger AG, Basel
\end{abstract}




\section{Case Reports in Dermatology}

\section{Introduction}

Sweet's syndrome is an acute febrile neutrophilic dermatosis characterized by neutrophilic erythema and fever [1]. The diagnosis of Sweet's syndrome is established by the presence of 2 major and at least 2 minor criteria. Major criteria include: (1) the abrupt onset of painful erythematous plaques or nodules, occasionally with vesicles, pustules, or bullae; and (2) neutrophilic infiltrates in the dermis without leukocytoclastic vasculitis. Minor criteria include: (1) a preceding nonspecific respiratory or gastrointestinal tract infection or vaccination, or an association with inflammatory disease, hemoproliferative disorder, solid malignant tumor, or pregnancy; (2) constitutional symptoms and fever; (3) leukocytosis; and (4) excellent response to treatment with systemic corticosteroids [2].

Cytokines play an etiologic role, directly and/or indirectly, in the development of Sweet's syndrome [3]. Granulocyte colony-stimulating factor (G-CSF), granulocyte macrophage colony-stimulating factor, interleukin (IL)-1 $\beta$, IL-6, IL-8, and tumor necrosis factor (TNF)- $\alpha$ are potential cytokine candidates [4, 5]. Particularly, serum G-CSF levels have been reported to be significantly higher in patients with active Sweet's syndrome compared to that in patients with inactive status [4].

Systemic corticosteroids, colchicine, and potassium iodide are first-line treatment options for Sweet's syndrome [6]. Second-line therapies include nonsteroidal anti-inflammatory drugs, dapsone, clofazimine, cyclosporine, and thalidomide. However, this disease may recur following either spontaneous remission or therapy-induced clinical resolution. The efficacy of rituximab [1], anti-TNF- $\alpha$ agents [7], and IL-1 receptor antagonists [8, 9] has been reported in refractory Sweet's syndrome. However, these agents sometimes cause adverse effects including serious infections, interstitial pneumonitis, and liver dysfunction. Although granulocyte and monocyte adsorption apheresis (GMA) therapy has significant efficacy with no safety concerns in pustular psoriasis [10,11], ulcerative colitis [12], and pyoderma gangrenosum [13], its efficacy in Sweet's syndrome has only been reported in 1 case [14]. GMA is an extracorporeal apheresis that removes activated granulocytes and monocytes using a column packed with cellulose acetate beads (Adacolumn; JIMRO, Takasaki, Japan) [12]. Herein, we present the successful treatment of a patient with recurrent Sweet's syndrome by GMA therapy, which was associated with the restoration of elevated serum G-CSF level.

\section{Case Report}

A 55-year-old Japanese woman with an underlying atopic dermatitis since childhood exhibited edema and erythematous lesions with pain on her four extremities, trunk, and neck (Fig. 1a). She also had a fever (body temperature $>39^{\circ} \mathrm{C}$ ). Laboratory findings were as follows: leukocyte count, 13,700/ $\mathrm{L}$ ( $86.5 \%$ of neutrophils); C-reactive protein (CRP), 7.27 $\mathrm{mg} / \mathrm{dL}$; and serum albumin, $3.5 \mathrm{~g} / \mathrm{dL}$. Other laboratory data were within normal ranges. Histological findings from the erythema on the right thigh revealed remarkable neutrophil infiltration in the dermis and subcutaneous tissue without leukocytoclastic vasculitis (Fig. $1 b, c)$. From these findings, the patient was diagnosed with Sweet's syndrome [2]. Oral administration of prednisolone (PSL) at $0.6 \mathrm{mg} / \mathrm{kg} /$ day was effective; thus, the dose was gradually tapered. However, the same symptoms recurred after 3 months, and further recurred 6 times within 2 years. At each recurrence, she was treated with $0.6 \mathrm{mg} / \mathrm{kg} / \mathrm{day}$ of PSL. Although PSL $0.15-0.3 \mathrm{mg} / \mathrm{kg} /$ day was continued for the next 3 years as a maintenance dose, 
the symptoms recurred 5 more times. Nonsteroidal anti-inflammatory drugs were ineffective, and colchicine was discontinued due to adverse effects such as nausea and headache. Preceding triggers such as infection, malignancy, or drugs could not be identified. PSL was discontinued 7 years after the initial onset, and blood tests were performed periodically every 2-3 months.

She visited us again due to multiple exudative erythema with pain on the trunk and upper extremities with fever $\left(>39^{\circ} \mathrm{C}\right)$ lasting for 7 days. Laboratory findings were as follows: leukocyte count, $9,960 / \mu \mathrm{L}$ ( $84.8 \%$ of neutrophils); CRP, $6.65 \mathrm{mg} / \mathrm{dL}$; serum amyloid A protein (SAA), $725 \mu \mathrm{g} / \mathrm{mL}$ (normal $<8.0 \mu \mathrm{g} / \mathrm{mL}$ ); and G-CSF $297 \mathrm{pg} / \mathrm{mL}$ (normal $<39 \mathrm{pg} / \mathrm{mL}$ ). She was diagnosed with a recurrence of Sweet's syndrome, and was treated with GMA therapy once a week for 3 consecutive weeks without any other treatments. The day after the first session of GMA therapy, all symptoms including erythema and fever were completely resolved. After 1 week, serum G-CSF level was significantly reduced to $<0.19 \mathrm{pg} / \mathrm{mL}$. Leukocyte count, neutrophil count, and serum SAA and CRP levels were also reduced, and were restored within normal ranges by 2 weeks (Fig. 2). The symptoms have not appeared for at least 4 months without oral administration of PSL.

\section{Discussion}

Innate immune disorders include: (1) autoinflammatory diseases such as deficiency of IL-36 receptor antagonist (DITRA), pyoderma gangrenosum, acne, and suppurative hidradenitis syndrome (PASH), and familial Mediterranean fever; and (2) neutrophilic diseases such as Sweet's syndrome and pyoderma gangrenosum [15]. Although both types of disease are described as distinct, they show many overlapping clinical, pathogenetic, histological, and genetic features [15]. Mutations in $M E F V$, an autoinflammatory gene, have been identified in some cases of Sweet's syndrome [16]. GMA therapy has shown efficacy in several autoinflammatory and neutrophilic diseases such as PASH syndrome [17], DITRA (pustular psoriasis) [18], palmoplantar pustulosis [19], and Behçet's disease [20]. Although the efficacy of GMA therapy in Sweet's syndrome has been reported in 1 patient [14], it has not been fully described. In the present case, GMA therapy resulted in a rapid and significant response with reduced clinical symptoms and restoration of abnormal laboratory findings, similar to that reported in patients with the above diseases.

Sweet's syndrome presents in several clinical settings: classical (or idiopathic), malignancy-associated (including leukemia), and drug-induced. It is also well known to be associated with autoimmune diseases such as Sjögren's syndrome and rheumatoid arthritis, and inflammatory bowel diseases such as ulcerative colitis and Crohn's disease [6]. The administration of G-CSF is responsible for the majority of cases with drug-induced Sweet's syndrome [6]. The present case had no associated diseases except for atopic dermatitis. Although she had not been administered G-CSF, her serum G-CSF level was elevated during the active phase of the recurrent Sweet's syndrome. The elevated G-CSF level dropped in response to GMA therapy (Fig. 2), indicating that high levels of G-CSF may be a useful indicator of activity in Sweet's syndrome. In addition, G-CSF-induced suppression of neutrophil apoptosis appears to be deeply involved in the pathogenesis of Sweet's syndrome [4]. Dysregulation of neutrophil homeostasis results in excessive inflammation and subsequent tissue damage. These findings support the hypothesis that activated granulocyte and monocytes play a major role in the immunopathogenesis of Sweet's syndrome, and the removal of these 
cells by GMA therapy is an expedient mechanism-based therapy. Clinical studies are needed to fully evaluate the efficacy and safety of GMA for refractory Sweet's syndrome.

\section{Statement of Ethics}

The patient has given her informed consent for the publication of her case.

\section{Disclosure Statement}

The authors have no conflicts of interest to disclose. There was no funding support for this work.

\section{References}

1 Seminario-Vidal L, Guerrero C, Sami N: Refractory Sweet's syndrome successfully treated with rituximab. JAAD Case Rep 2015;1:123-125.

-2 Fett DL, Gibson LE, Su WP: Sweet's syndrome: systemic signs and symptoms and associated disorders. Mayo Clin Proc 1995;70:234-240.

3 Reuss-Borst MA, Pawelec G, Saal JG, Horny HP, Müller CA, Waller HD: Sweet's syndrome associated with myelodysplasia: possible role of cytokines in the pathogenesis of the disease. Br J Haematol 1993;84:356-358.

-4 Kawakami T, Ohashi S, Kawa Y, Takahama H, Ito M, Soma Y, Mizoguchi M: Elevated serum granulocyte colony-stimulating factor levels in patients with active phase of Sweet syndrome and patients with active Behçet disease: implication in neutrophil apoptosis dysfunction. Arch Dermatol 2004;140:570574.

5 Marzano AV, Fanoni D, Antiga E, Quaglino P, Caproni M, Crosti C, Meroni PL, Cugno M: Expression of cytokines, chemokines and other effector molecules in two prototypic autoinflammatory skin diseases, pyoderma gangrenosum and Sweet's syndrome. Clin Exp Immunol 2014;178:48-56.

-6 Cohen PR: Sweet's syndrome - a comprehensive review of an acute febrile neutrophilic dermatosis. Orphanet J Rare Dis 2007;2:34.

7 Foster EN, Nguyen KK, Sheikh RA, Prindiville TP: Crohn's disease associated with Sweet's syndrome and Sjögren's syndrome treated with infliximab. Int J Dermatol 2003;42:761-778.

-8 Kluger N, Gil-Bistes D, Guillot B, Bessis D: Efficacy of anti-interleukin-1 receptor antagonist anakinra (Kineret ${ }^{\circledR}$ ) in a case of refractory Sweet's syndrome. Dermatology 2011;222:123-127.

$\$ 9$ Delluc A, Limal N, Puéchal X, Francès C, Piette JC, Cacoub P: Efficacy of anakinra, an IL1 receptor antagonist, in refractory Sweet syndrome. Ann Rheum Dis 2008;67:278-279.

10 Ikeda S, Takahashi H, Suga Y, Eto H, Etoh T, Okuma K, Takahashi K, Kanbara T, Seishima M, Morita A, Imai Y, Kanekura T: Therapeutic depletion of myeloid lineage leukocytes in patients with generalized pustular psoriasis indicates a major role for neutrophils in the immunopathogenesis of psoriasis. J Am Acad Dermatol 2013;68:609-617.

-11 Fujisawa T, Murase K, Kanoh H, Takemura M, Ohnishi H, Seishima M: Adsorptive depletion of $\mathrm{CD} 14^{+} \mathrm{CD} 16^{+}$proinflammatory monocyte phenotype in patients with generalized pustular psoriasis: clinical efficacy and effects on cytokines. Ther Apher Dial 2012;16:436-444.

$\checkmark 12$ Andoh A, Tsujikawa T, Inatomi O, Deguchi Y, Hata K, Kitoh K, Sasaki M, Mitsuyama K, Fujiyama Y: Suppression of inflammatory cytokine secretion by granulocyte/monocyte adsorptive apheresis in active ulcerative colitis. Ther Apher Dial 2005;9:123-127.

13 Seishima M, Mizutani Y, Shibuya Y, Nagasawa C, Aoki T: Efficacy of granulocyte and monocyte adsorption apheresis for three cases of refractory pyoderma gangrenosum. Ther Apher Dial 2007;11:177-182.

14 Sakanoue M, Takeda K, Kawai K, Kanekura T: Granulocyte and monocyte adsorption apheresis for refractory skin diseases due to activated neutrophils, psoriasis, and associated arthropathy. Ther Apher Dial 2013;17:477-483.

15 Navarini AA, Satoh TK, French LE: Neutrophilic dermatoses and autoinflammatory diseases with skin involvement - innate immune disorders. Semin Immunopathol 2016;38:45-56. 


\section{Case Reports in Dermatology}

\begin{tabular}{l|l}
\hline Case Rep Dermatol 2017;9:13-18 \\
\hline DOI: $10.1159 / 000475878$ & $\begin{array}{l}\text { ○ 2017 The Author(s). Published by S. Karger AG, Basel } \\
\text { www.karger.com/cde }\end{array}$ \\
\hline
\end{tabular}

Fujii et al.: Sweet's Syndrome Successfully Treated with Granulocyte and Monocyte Adsorption Apheresis

16 Jo T, Horio K, Migita K: Sweet's syndrome in patients with MDS and MEFV mutations. N Engl J Med 2015;372:686-688.

17 Mizutani Y, Okano T, Takahashi T, Ohnishi H, Ohara O, Sano A, Seishima M: Pyoderma gangrenosum, acne and suppurative hidradenitis syndrome treated with granulocyte and monocyte adsorption apheresis. Acta Derm Venereol 2017;97:275-276.

18 Sugiura K, Haruna K, Suga Y, Akiyama M: Generalized pustular psoriasis caused by deficiency of interleukin-36 receptor antagonist successfully treated with granulocyte and monocyte adsorption apheresis. J Eur Acad Dermatol Venerol 2014;28:1835-1836.

19 Fujisawa T, Tawada C, Mizutani Y, Doi T, Yoshida S, Ogura S, Seishima M: Efficacy of granulocyte and monocyte adsorption apheresis for treatment of palmoplantar pustulosis. Ther Apher Dial 2014;18:238-243.

20 Kanekura T, Gushi A, Iwata M, Fukumaru S, Sakamoto R, Kawahara K, Maruyama I, Kanzaki T: Treatment of Behçet's disease with granulocyte and monocyte adsorption apheresis. J Am Acad Dermatol 2004;51:S83-S87.

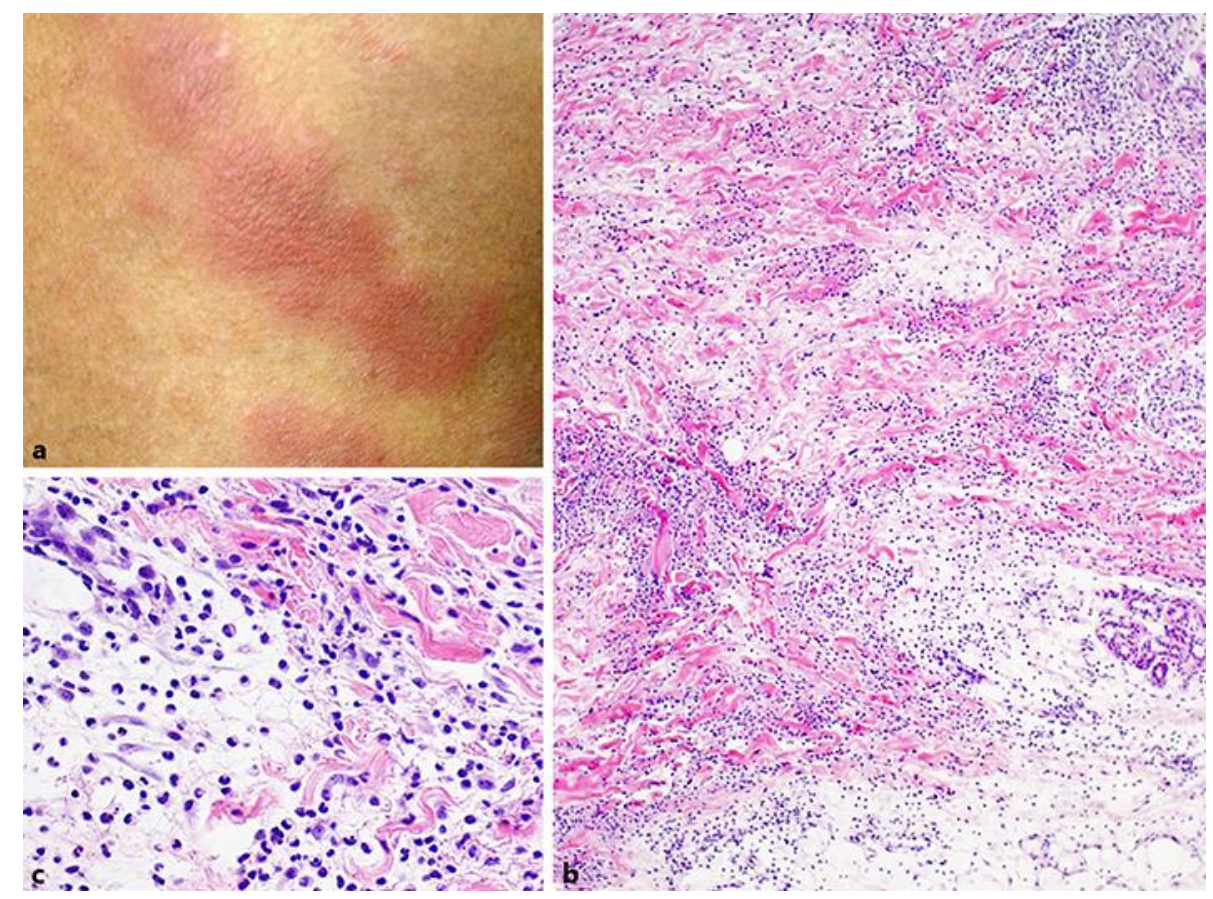

Fig. 1. a Clinical features on the patient's back at the first visit. Histopathological findings of a biopsy specimen from erythema (hematoxylin-eosin) (original magnification $\times 40$; b) (original magnification $\times 200$; ). 


\section{Case Reports in Dermatology}

Case Rep Dermatol 2017;9:13-18 DOI: $10.1159 / 000475878$

(C) 2017 The Author(s). Published by S. Karger AG, Basel

Fujii et al.: Sweet's Syndrome Successfully Treated with Granulocyte and Monocyte Adsorption Apheresis

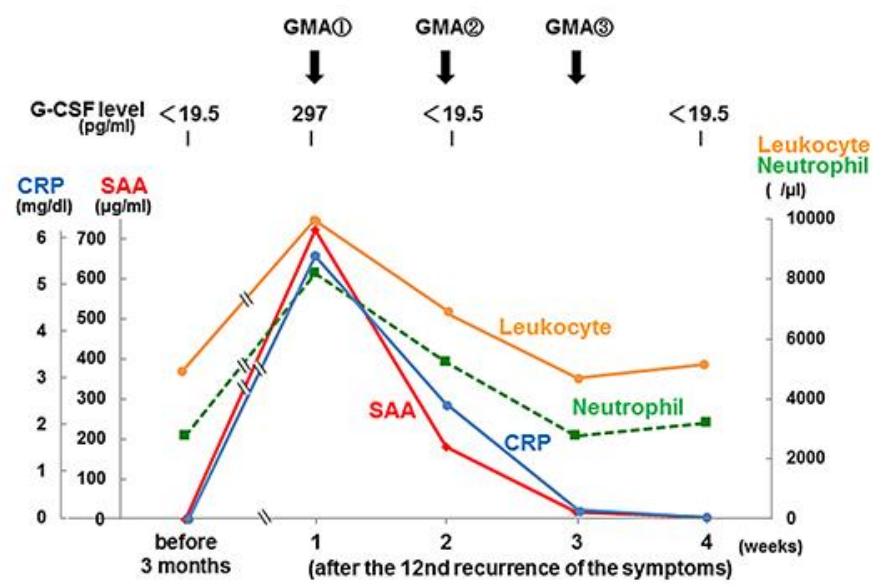

Fig. 2. The time course of laboratory data after granulocyte and monocyte adsorption apheresis (GMA) therapy. 